\title{
Just think about pyogenic spondylodiscitis before performing the epidural steroid injection for low back pain
}

\author{
Yusuke Asakura \\ Department of Anesthesiology, Nagoya Kyoritsu Hospital, Aichi, Japan
}

An epidural steroid injection (ESI) is a commonly performed procedure to relieve low back pain (LBP) [1]. The underlying pathological condition of LBP encompasses a wide spectrum of diseases, and the clinical diagnosis requires a complex decision-making process. Among which, pyogenic spondylodiscitis entails major morbidity and mortality, and is an absolute contraindication for ESI [2]. The major clinical symptom of pyogenic spondylodiscitis is the pain, particularly LBP, with a prevalence $>90 \%$ in patients [3]. Therefore, we preclude the presence of pyogenic discitis before performing an ESI.

To evaluate and understand more fully the clinical manifestations of pyogenic spondylodiscitis, we extracted all medical charts of patients in our facility diagnosed as such, based on International Classification of Diseases-10 coding, after Institutional Review Board approval was obtained. The following variables were reviewed retrospectively from the medical charts: age, sex, clinical manifestations, white blood cell (WBC) count, C-reactive protein (CRP), magnetic resonance imaging (MRI) findings, blood culture, and fluoroscopy-guided biopsy and tissue culture of infected discs.

We identified 26 patients during the 10-year period from 2006 to 2015. The following patients were excluded from the analysis: those who had already been diagnosed with pyogenic

Corresponding author: Yusuke Asakura, M.D.

Department of Anesthesiology, Nagoya Kyoritsu Hospital, 1-172 Hokke, Nakagawa-ku, Nagoya, Aichi 454-0933, Japan

Tel: 81-52-362-5151, Fax: 81-52-353-9105

Email: yasakura@kaikou.or.jp

ORCID: https://orcid.org/0000-0003-3966-1757 spondylodiscitis (recurrent cases) and those who had developed pyogenic spondylodiscitis following any spinal surgery (surgical site infection cases). Accordingly, 18 "de novo" cases were analyzed. The detailed characteristics of the patients are summarized in Table 1.

The chief complaint of 14 of the 18 patients was LBP. A WBC count $\geqq 11,000 / \mu$ l was observed in six individuals and WBC counts were $<9,600 / \mu$ in nine cases. Similarly, CRP level was $<3 \mathrm{mg} / \mathrm{dl}$ in six cases. In contrast, MRI findings suggesting the presence of pyogenic spondylodiscitis (T1 low/T2 high/fast imaging employing steady-state acquisition high) were detected in all cases. Fluoroscopy-guided biopsy and tissue culture of infected discs were carried out in 12 cases, and pathogenic microbes were detected in four cases. Only two cases were positive for blood culture. In all cases, the inflammation resolved without any neurological complications following administration of an appropriate antibiotic, and no surgical procedures were required. Notably, ESI had been performed for LBP before any diagnostic procedures had been performed either at the other department or at other facilities in eight of the 18 cases.

In conclusion, LBP is a common chief complaint of spinal infection. Blood examinations, such as WBC count and CRP, are of limited value, whereas the sensitivity of MRI findings is high. Fluoroscopy-guided biopsy and tissue culture of the infected disc (s) provide good clues for the diagnosis and treatment of pyogenic spondylodiscitis, but the sensitivity of a blood culture is not sufficient. Diagnostic procedures to identify the etiology of the corresponding LBP must be carried out before performing any interventional procedures, including ESI for LBP.

Received: August 30, 2017.

Accepted: September 4, 2017.

Korean J Anesthesiol 2018 April 71(2): 161-162

https://doi.org/10.4097/kjae.2018.71.2.161

(c) This is an open-access article distributed under the terms of the Creative Commons Attribution Non-Commercial License (http://creativecommons.org/ licenses/by-nc/4.0/), which permits unrestricted non-commercial use, distribution, and reproduction in any medium, provided the original work is properly cited. 
Table 1. Clinical Manifestations and Characteristics of the Patients with Pyogenic Spondylodiscitis

\begin{tabular}{|c|c|c|c|c|c|c|c|c|c|}
\hline Sex & Age & $\begin{array}{c}\text { Chief } \\
\text { complaint(s) }\end{array}$ & $\begin{array}{c}\text { Infected } \\
\text { discs and } \\
\text { vertebrates }\end{array}$ & $\begin{array}{l}\text { WBC } \\
\text { count }\end{array}$ & $\begin{array}{l}\text { C-reactive } \\
\text { protein }\end{array}$ & $\begin{array}{c}\text { MRI } \\
\text { findings }\end{array}$ & $\begin{array}{l}\text { Biopsy of } \\
\text { infected } \\
\text { discs }\end{array}$ & $\begin{array}{l}\text { Therapy and } \\
\text { clinical outcome }\end{array}$ & $\begin{array}{c}\text { Pre- } \\
\text { diagnostic } \\
\text { block therapy }\end{array}$ \\
\hline Female & 54 & LBP & L4, L5 & 5200 & 0.05 & Yes & Yes & Conservative & No \\
\hline Female & 84 & LBP & L3 & 6300 & 0.1 & Yes & No & Conservative & Yes \\
\hline Male & 59 & LBP & L4, L5 & 7100 & 1.5 & Yes & Yes & Conservative & No \\
\hline Female & 69 & Backache & Th7, Th8 & 7200 & 1.3 & Yes & No & Conservative & No \\
\hline Male & 55 & LBP & L4, L5, S & 7200 & 7.1 & Yes & Yes & Conservative & Yes \\
\hline Male & 72 & LBP & L4, L5 & 8100 & 7.0 & Yes & Yes & Conservative & Yes \\
\hline Male & 73 & LBP & L3 & 8300 & 4.8 & Yes & No & Conservative & Yes \\
\hline Female & 75 & LBP & L4, L5 & 9100 & 5.3 & Yes & Yes & Conservative & Yes \\
\hline Female & 83 & LBP & L5 & 9600 & 11.7 & Yes & Yes & Conservative & No \\
\hline Male & 79 & Fever & Th11, 12 & 10000 & 1.6 & Yes & No & Conservative & Yes \\
\hline Male & 50 & Cervical pain & $\mathrm{C} 6,7$ & 10000 & 3.1 & Yes & No & Conservative & No \\
\hline Male & 72 & LBP & Th12, L1 & 10300 & 3.1 & Yes & Yes & Conservative & No \\
\hline Female & 73 & LBP & $\mathrm{L} 2,3$ & 11000 & 25.8 & Yes & Yes & Conservative & No \\
\hline Male & 74 & LBP & L3, 4 & 12400 & 13.3 & Yes & Yes & Conservative & No \\
\hline Male & 88 & LBP & L4 & 12500 & 6.5 & Yes & No & Conservative & No \\
\hline Male & 61 & LBP & L1, L5, S1 & 13600 & 2.3 & Yes & Yes & Conservative & Yes \\
\hline Female & 83 & Fever & Th11-L1 & 14300 & 7.4 & Yes & Yes & Conservative & No \\
\hline Female & 55 & LBP & $\mathrm{L} 4,5$ & 15800 & 24.4 & Yes & Yes & Conservative & Yes \\
\hline
\end{tabular}

\section{References}

1. Cohen SP, Hanling S, Bicket MC, White RL, Veizi E, Kurihara C, et al. Epidural steroid injections compared with gabapentin for lumbosacral radicular pain: multicenter randomized double blind comparative efficacy study. BMJ 2015; 350: h1748.

2. Skaf GS, Domloj NT, Fehlings MG, Bouclaous CH, Sabbagh AS, Kanafani ZA, et al. Pyogenic spondylodiscitis: an overview. J Infect Public Health 2010; 3: 5-16.

3. Sapico FL, Montgomerie JZ. Pyogenic vertebral osteomyelitis: report of nine cases and review of the literature. Rev Infect Dis 1979; 1: 75476. 